\title{
Chickadees with Bigger Brains Have Smaller Digestive Tracts: A Multipopulation Comparison
}

\author{
Dovid Y. Kozlovsky a, b Shelby L. Brown ${ }^{a} \quad$ Carrie L. Branch ${ }^{a, b}$ \\ Timothy C. Roth II ${ }^{c}$ Vladimir V. Pravosudova,b \\ ${ }^{a}$ Department of Biology, and ${ }^{b}$ Graduate Program in Ecology, Evolution and Conservation Biology, University of \\ Nevada, Reno, Nev., and ' Department of Psychology, Biological Foundations of Behavior Program, Franklin and \\ Marshall College, Lancaster, Pa., USA
}

\section{Key Words}

Chickadee · Expensive tissue - Cognition - Stomach .

Guts - Brain size

\begin{abstract}
The factors leading to the evolution of large brain size remain controversial. Brains are metabolically expensive and larger brains demand higher maintenance costs. The expensive-tissue hypothesis suggests that when selection favors larger brains, evolutionary changes in brain size can occur without an overall increase in energetic costs when brain size represents a trade-off with the size of other expensive tissues, such as the digestive tract. Still, support for this hypothesis is equivocal. We compared mean brain mass, digestive tract mass (stomach and gut) and heart mass in 9 populations of black-capped chickadees along a gradient of winter climate severity. Mean brain mass and telencephalon volume showed significant population variation with larger brains associated with harsher winter conditions. Mean population brain mass and telencephalon volume were also negatively related to both stomach and gut mass. Mean population heart mass, on the other hand, was not signifi-
\end{abstract}

\section{KARGER}

E-Mail karger@karger.com

www.karger.com/bbe cantly associated with either mean brain mass or winter climate severity. Mean brain mass was negatively associated with body mass, with chickadees from harsher environments being smaller but having larger brains and smaller digestive tracts. Our results are consistent with the expensive-tissue hypothesis, and suggest that a harsher winter climate might favor larger brains, which might be associated with a reduction in size of the digestive tract. These findings could potentially be a result of population differences in the winter climate diet related to the perishability of more efficient invertebrate-based food caches.

(c) 2014 S. Karger AG, Basel

\section{Introduction}

Brains are metabolically demanding organs that have substantial energetic requirements, and, as such, largerbrained organisms should have higher basal metabolic rates [Mink et al., 1981; Aiello and Wheeler, 1995; Isler and van Schaik, 2006]. One hypothesis explaining the evolution of large brains without a corresponding increase in total energetic demands is the expensive-tissue 
hypothesis [Aiello and Wheeler, 1995]. It is important to note here that the expensive-tissue hypothesis does not explain the reason for the evolution of larger brains, but instead attempts to explain potential trade-offs associated with the evolution of larger brains when there is selection pressure on brain size either due to harsh environments or complex sociality. The expensive-tissue hypothesis proposes that energetic demands for larger brains (favored by some environmental conditions) could be offset by a reduction in other energetically expensive tissues such as in the digestive tract [Aiello and Wheeler, 1995]. In other words, when there is a strong selection on brain size, the evolutionary enlargement of the brain can occur at the expense of some other expensive tissues. Yet, comparisons of brain and gastrointestinal size (the most plastic of these organs) have yielded equivocal results [Aiello and Wheeler, 1995; Hladik et al., 1999; Fish and Lockwood, 2002; Kauffman, 2003; Jones and MacLarnon, 2004; Isler and van Schaik, 2006; Barrickman and Lin, 2010; Navarrete et al., 2011; Kotrschal et al., 2013], while comparisons of the brain and other expensive organs (such as the heart, liver, testes or skeletal muscles) have mostly failed to find a correlation between brain size and other expensive tissue [Isler and van Schaik, 2006; Navarrete et al., 2011; Warren and Iglesias, 2012], with a few exceptions, e.g. the skeletal muscle [Isler and van Schaik, 2006].

Here, we used food-caching black-capped chickadees (Poecile atricapillus) from multiple populations sampled across a continent-wide gradient of winter climate harshness in North America. Previously, we showed a significant population variation in hippocampal morphology and cognition in this species and argued that such variation is due to differential winter climate-related selection pressures on the spatial memory needed for cache retrieval [Roth and Pravosudov, 2009; Roth et al., 2011]. As these populations also show significant variations in brain size, they represent a prime opportunity for investigating, at a population level, the hypothesized trade-off between the size of the brain and the digestive tract by comparing populations that experience significant differences in environmental conditions [Pravosudov et al., 2012]. Using a population-comparative analysis might minimize potential confounds associated with interspecies analyses, particularly as different species show tremendous variations in their diet and alimentary tracts [Chivers and Hladik, 1980; Ricklefs, 1996; Hladik et al., 1999]. We predicted that chickadees from populations with harsher climates should have larger brains and smaller digestive tracts.

Chickadees with Bigger Brains Have

Smaller Digestive Tracts

\section{Materials and Methods}

We used nonmigratory black-capped chickadees from 9 populations across a gradient of winter climate harshness, that had been collected for our previous studies focusing on the relationship between winter climate harshness, cache-related spatial memory and the hippocampus [Roth and Pravosudov, 2009; Roth et al., 2011]. All animals were caught and sacrificed according to the protocols, collecting-permits and animal-care approvals reported previously [Roth and Pravosudov, 2009; Roth et al., 2011]. In our previous studies, we used 10 populations, but, unfortunately, the bodies of the birds from one of these populations (from Colorado) were accidentally discarded and therefore not available for any further analyses. So we used chickadees from the remaining 9 populations. Data on brain mass, body mass (measured at collection), tarsus length, wing length, telencephalon and hippocampus volumes were taken directly from our previous studies [Roth and Pravosudov, 2009; Roth et al., 2011]. All birds were collected in the morning during the same season, autumn (September-October) when birds in all populations usually experience a superabundance of naturally available food, are engaged in long-term food caching, and when weather conditions are relatively mild across all locations. Birds were trapped early in the day and perfused following capture. Body mass was measured immediately before perfusion and so all birds were measured at approximately the same time of day across all collection locations. Birds were perfused with $10 \%$ methanol-free formalin and their brains were extracted, weighed and frozen. Following perfusion, those bird bodies with an intact digestive tract were stored in sealed plastic bags in a refrigerator until the autumn of 2013. All bodies and intestines were preserved in formalin as a result of perfusion and were never frozen, so differences in timing of collection (the birds were collected in 2007 and 2008) should not be an issue. At the same time, perfusion prevented obtaining dry mass because all birds had to be perfused following capture, as required for the histological brain analyses.

All birds were dissected by S.L.B. under a stereomicroscope, and the stomach (gizzard and proventriculus), guts (intestines) and hearts were separated and then weighed to the nearest $0.0001 \mathrm{~g}$. The hearts were measured as a control for a potential association between brain size and digestive tract size. All tissue was dried using Kimwipes prior to weighing. For the stomach and gut mass, we used 99 chickadees from 9 populations ranked from the harshest (1) to the mildest (9) environment: Fairbanks, Alaska, USA (1), Anchorage, Alaska, USA (2), Presque Isle, Me., USA (3), Prince George, B.C., Canada (4), Grant, Minn., USA (5), Missoula, Mont., USA (6), Mt. Vernon, Iowa, USA (7), Manhattan, Kans., USA (8) and Seattle, Wash., USA (9) (table 1). For hearts, only 85 birds were used, as in each population, there were some that were not fully intact following extraction. We combined winter climate data from our 2 previous studies (4 from Roth and Pravosudov [2009] and 5 from Roth et al. [2011]) to generate ranks for the 9 populations used here. Winter climate ranks were based on average air temperature over 6 winter months (November-March) averaged from 1971 to 2000 using publicly available weather databases (see Roth and Pravosudov [2009]). A correlation between average winter temperature and climate harshness rank was perfect (Spearman $\left.r_{s}=1\right)$.

All analyses were performed on a population level as in our 2 previous studies. Our overarching hypothesis is that populations experiencing different selection pressures due to differences in 
Table 1. Population measurements

\begin{tabular}{|c|c|c|c|c|c|c|c|c|c|}
\hline Location $^{\mathrm{a}}$ & Stomach mass, $\mathrm{g}$ & Gut mass, $g$ & Heart mass, g & Brain mass, $\mathrm{g}$ & Body mass, g & $\begin{array}{l}\text { TEL (minus Hp) } \\
\text { volume, } \mathrm{mm}^{3}\end{array}$ & $\begin{array}{l}\text { Hp volume, } \\
\mathrm{mm}^{3}\end{array}$ & $\begin{array}{l}\text { Tarsus length, } \\
\mathrm{mm}\end{array}$ & $\begin{array}{l}\text { Wing length, } \\
\mathrm{mm}\end{array}$ \\
\hline $\operatorname{AKF}(1)$ & $0.49(0.05,8)$ & $0.49(0.03,8)$ & $0.14(0.01,7)$ & $0.77(0.02,13)$ & $11.38(0.22,13)$ & $494.3(17.5,13)$ & $28.15(0.72,13)$ & $15.67(0.22,14)$ & $66.11(0.63,14)$ \\
\hline $\mathrm{AKA}(2)$ & $0.32(0.04,12)$ & $0.37(0.03,12)$ & $0.13(0.01,9)$ & $0.80(0.02,12)$ & $11.10(0.23,12)$ & $511.4(18.3,12)$ & $27.20(0.75,12)$ & $15.73(0.24,12)$ & $66.04(0.68,12)$ \\
\hline ME (3) & $0.43(0.05,10)$ & $0.41(0.03,10)$ & $0.13(0.01,19)$ & $0.78(0.02,12)$ & $11.60(0.23,12)$ & $497.1(18.3,12)$ & $26.08(0.75,12)$ & $15.71(0.24,12)$ & $67.50(0.68,12)$ \\
\hline $\mathrm{BC}(4)$ & $0.33(0.04,11)$ & $0.34(0.03,11)$ & $0.10(0.01,6)$ & $0.80(0.02,12)$ & $10.79(0.22,13)$ & $503.3(18.3,12)$ & $26.29(0.75,12)$ & $15.66(0.23,13)$ & $66.58(0.65,13)$ \\
\hline MN (5) & $0.57(0.05,10)$ & $0.31(0.03,10)$ & $0.11(0.01,7)$ & $0.78(0.02,12)$ & $11.64(0.23,12)$ & $497.2(18.3,12)$ & $25.91(0.75,12)$ & $16.76(0.24,12)$ & $65.54(0.68,12)$ \\
\hline MT (6) & $0.55(0.04,12)$ & $0.42(0.03,12)$ & $0.13(0.01,12)$ & $0.73(0.02,12)$ & $11.42(0.23,12)$ & $446.9(18.3,12)$ & $25.07(0.75,12)$ & $15.24(0.24,12)$ & $65.83(0.68,12)$ \\
\hline IA (7) & $0.57(0.04,12)$ & $0.37(0.03,12)$ & $0.14(0.01,10)$ & $0.74(0.02,12)$ & $12.11(0.23,12)$ & $482.5(18.3,12)$ & $24.06(0.75,12)$ & $16.10(0.24,12)$ & $65.08(0.68,12)$ \\
\hline KS (8) & $0.62(0.04,13)$ & $0.42(0.02,13)$ & $0.16(0.01,11)$ & $0.74(0.02,13)$ & $12.84(0.22,13)$ & $459.1(17.5,13)$ & $23.15(0.72,13)$ & $15.26(0.23,13)$ & $69.15(0.65,13)$ \\
\hline WA (9) & $0.57(0.04,11)$ & $0.38(0.03,11)$ & $0.11(0.01,11)$ & $0.70(0.02,13)$ & $11.19(0.22,13)$ & $430.2(17.5,13)$ & $22.65(0.72,13)$ & $16.52(0.23,13)$ & $61.69(0.65,13)$ \\
\hline $\mathrm{GLM}^{\mathrm{b}}$ & $\begin{array}{l}\mathrm{F}_{8,90}=6.41 \\
\mathrm{p}<0.001\end{array}$ & $\begin{array}{l}\mathrm{F}_{8,90}=3.32 \\
\mathrm{p}=0.002\end{array}$ & $\begin{array}{l}\mathrm{F}_{8,74}=7.11 \\
\mathrm{p}<0.001\end{array}$ & $\begin{array}{l}\mathrm{F}_{8,102}=3.18 \\
\mathrm{p}=0.003\end{array}$ & $\begin{array}{l}\mathrm{F}_{8,103}=7.37 \\
\mathrm{p}<0.001\end{array}$ & $\begin{array}{l}\mathrm{F}_{8,102}=2.47 \\
\mathrm{p}=0.017\end{array}$ & $\begin{array}{l}\mathrm{F}_{8,102}=6.34 \\
\mathrm{p}<0.001\end{array}$ & $\begin{array}{l}\mathrm{F}_{8,104}=4.83 \\
\mathrm{p}<0.001\end{array}$ & $\begin{array}{l}\mathrm{F}_{8,104}=9.42 \\
\mathrm{p}<0.001\end{array}$ \\
\hline
\end{tabular}

Values are the least-squares means (least-squares SE, sample size) from GLM models. The populations are ranked by winter climate severity determined by the average air temperature during the winter (November-March); (1) is the harshest and (9) is the mildest. Birds from AKF, BC, MT and KS were collected in 2007. Birds from AKA, ME, MN, WA and IA were collected in 2008. GLM = General linear model; Hp = hippocampus; TEL $=$ telencephalon. a The locations of the bird populations have been abbreviated: AKF = Alaska Fair banks, $\mathrm{AKA}=$ Alaska Anchorage, $\mathrm{ME}=$ Maine, $\mathrm{BC}=$ British Columbia, $\mathrm{MN}=\mathrm{Min}$ nesota, $\mathrm{MT}=$ Montana, IA = Iowa, $\mathrm{KS}=$ Kansas, WA = Washington .

$\mathrm{b}$ This was used to test for population differences in all measurements. winter climate harshness should diverge with regard to a number of traits, such as spatial memory and hippocampus morphology. In addition, we have also documented significant population differences in neophobia and problem-solving [Roth et al., 2012] which suggest that climatic variation might result in differences in multiple cognitive traits and in brain morphology. We therefore used population-level comparisons using populations as independent statistical replicates. To incorporate within-population variation in our analyses, we used the ordered-heterogeneity test [Rice and Gaines, 1994] by ranking populations based on (1) winter climate harshness, (2) mean brain mass, (3) mean digestive tract mass and (4) mean heart mass as another organ which could potentially trade off with brain size (control). Using the ordered-heterogeneity tests, we specifically tested whether (1) mean population digestive tract mass declines with an increase in mean population brain mass, (2) mean population heart mass declines with an increase in mean population brain mass and (3) mean brain mass increases with an increase in winter climate harshness. In our previous studies [Roth and Pravosudov, 2009; Roth et al., 2011], we reported mean brain mass, but we did not analyze the relationship between winter climate harshness and the overall brain mass or volume because our main goal was to test for climate-related differences in relative hippocampus volume independent of the rest of the brain. Here, we combine data from these studies; this provides a more robust test of potential association between the overall brain size and winter climate harshness.

\section{Results}

Mean gut mass and stomach mass were negatively associated with mean brain mass; larger brain mass was associated with smaller guts (fig. 1a, ordered-heterogeneity test, $\left.\mathrm{r}_{\mathrm{s}} \mathrm{P}_{\mathrm{c}}=0.432, \mathrm{k}=9, \mathrm{p}<0.05\right)$ and smaller stomachs (fig. 1b, ordered-heterogeneity test, $r_{s} P_{c}=0.633$, $\mathrm{p}<0.01)$ on a population level. Mean brain mass was also significantly and negatively associated with winter climate harshness (fig. 1d); birds from populations experiencing harsher winter climates had a larger brain mass (ordered-heterogeneity test, $\mathrm{r}_{\mathrm{s}} \mathrm{P}_{\mathrm{c}}=0.765, \mathrm{k}=9$, $\mathrm{p}<0.001)$.

Similar to brain mass, there was a negative association between telencephalon (minus the hippocampus) volume and mean population gut mass (ordered-heterogeneity test, $\left.\mathrm{r}_{\mathrm{s}} \mathrm{P}_{\mathrm{c}}=0.573, \mathrm{k}=9, \mathrm{p}<0.01\right)$ and stomach mass (ordered-heterogeneity test, $\mathrm{r}_{\mathrm{s}} \mathrm{P}_{\mathrm{c}}=0.583, \mathrm{k}=9, \mathrm{p}<0.01$ ). This is not surprising, considering that mean brain mass was tightly correlated with telencephalon volume (Spearman $\left.r_{s}=0.98\right)$. Like mean brain mass, mean telencephalon volume was negatively related to the winter climate harshness rank with larger telencephalons in harsher environments (ordered-heterogeneity test, $\mathrm{r}_{\mathrm{s}} \mathrm{P}_{\mathrm{c}}=0.720, \mathrm{k}=$ $9, \mathrm{p}<0.01)$. Mean hippocampus volume was negatively associated with mean stomach mass (ordered-heterogeneity test, $\mathrm{r}_{\mathrm{s}} \mathrm{P}_{\mathrm{c}}=0.733, \mathrm{k}=9, \mathrm{p}<0.01$ ), but not gut mass ( $p>0.2$ ); birds from populations with larger hippocampi had smaller stomachs. Mean population heart mass was not significantly associated with mean brain mass (fig. 1c, ordered-heterogeneity test, $\mathrm{r}_{\mathrm{s}} \mathrm{P}_{\mathrm{c}}=0.283, \mathrm{k}=9, \mathrm{p}>0.05$ ) or with winter climate harshness (ordered-heterogeneity test, $\left.\mathrm{r}_{\mathrm{s}} \mathrm{P}_{\mathrm{c}}=0.017, \mathrm{k}=9, \mathrm{p}>0.2\right)$.

Mean body mass was positively associated with winter climate harshness; birds were smaller in populations from harsher environments and larger in populations from milder environments (fig. $2 \mathrm{a}$, ordered-heterogeneity test, $\left.\mathrm{r}_{\mathrm{s}} \mathrm{P}_{\mathrm{c}}=0.416, \mathrm{k}=9, \mathrm{p}<0.05\right)$. At the same time, 

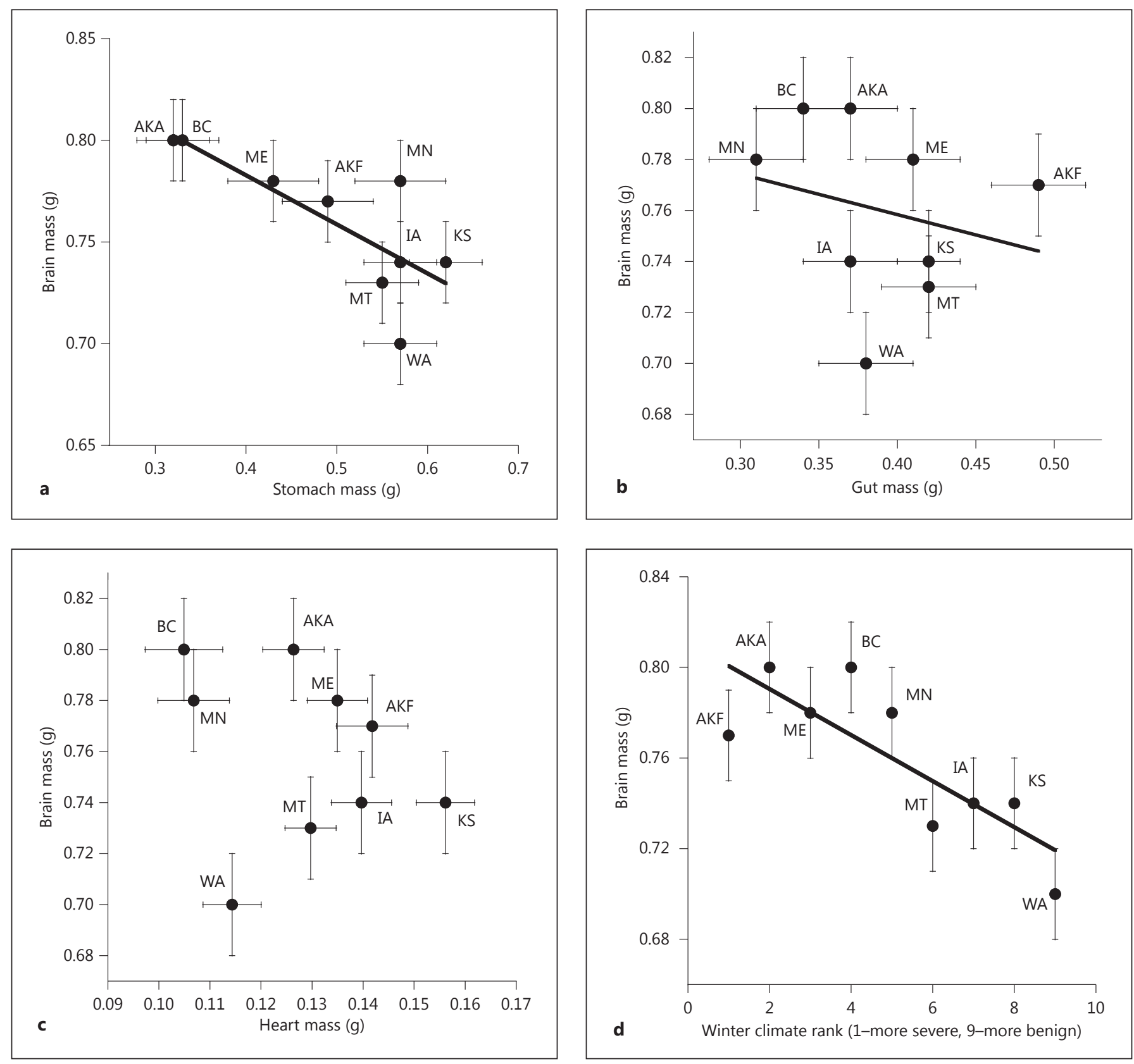

Fig. 1. The relationship between mean population brain mass and mean stomach mass (a), gut mass (b), heart mass (c) and winter climate harshness (d) for 9 populations of black-capped chickadees. See table 1 (footnote a) for the abbreviation of the locations.

body mass was negatively associated with mean brain mass with smaller birds having larger brains (fig. 2b, ordered-heterogeneity test, $\mathrm{r}_{\mathrm{s}} \mathrm{P}_{\mathrm{c}}=0.367, \mathrm{k}=9, \mathrm{p}<0.05$ ). Mean body mass was positively associated with stomach mass (ordered-heterogeneity test, $\mathrm{r}_{\mathrm{s}} \mathrm{P}_{\mathrm{c}}=0.816, \mathrm{k}=9, \mathrm{p}<$ 0.001 ), but not significantly associated with gut mass (ordered-heterogeneity test, $r_{s} P_{c}=0.267, k=9, p<0.1$ ).
Finally, the tarsus length (tarsometatarsus) also showed significant population variation (general linear model, $\mathrm{F}_{8,104}=4.83, \mathrm{p}<0.001$ ), but there were no significant associations between mean population tarsus length and climate (ordered-heterogeneity test, $\mathrm{r}_{\mathrm{s}} \mathrm{P}_{\mathrm{c}}=0.099, \mathrm{k}=$ $9, \mathrm{p}>0.2$ ), mean population brain mass (ordered-heterogeneity test, $\mathrm{r}_{\mathrm{s}} \mathrm{P}_{\mathrm{c}}=0.016, \mathrm{k}=9, \mathrm{p}>0.5$ ) or mean popula- 

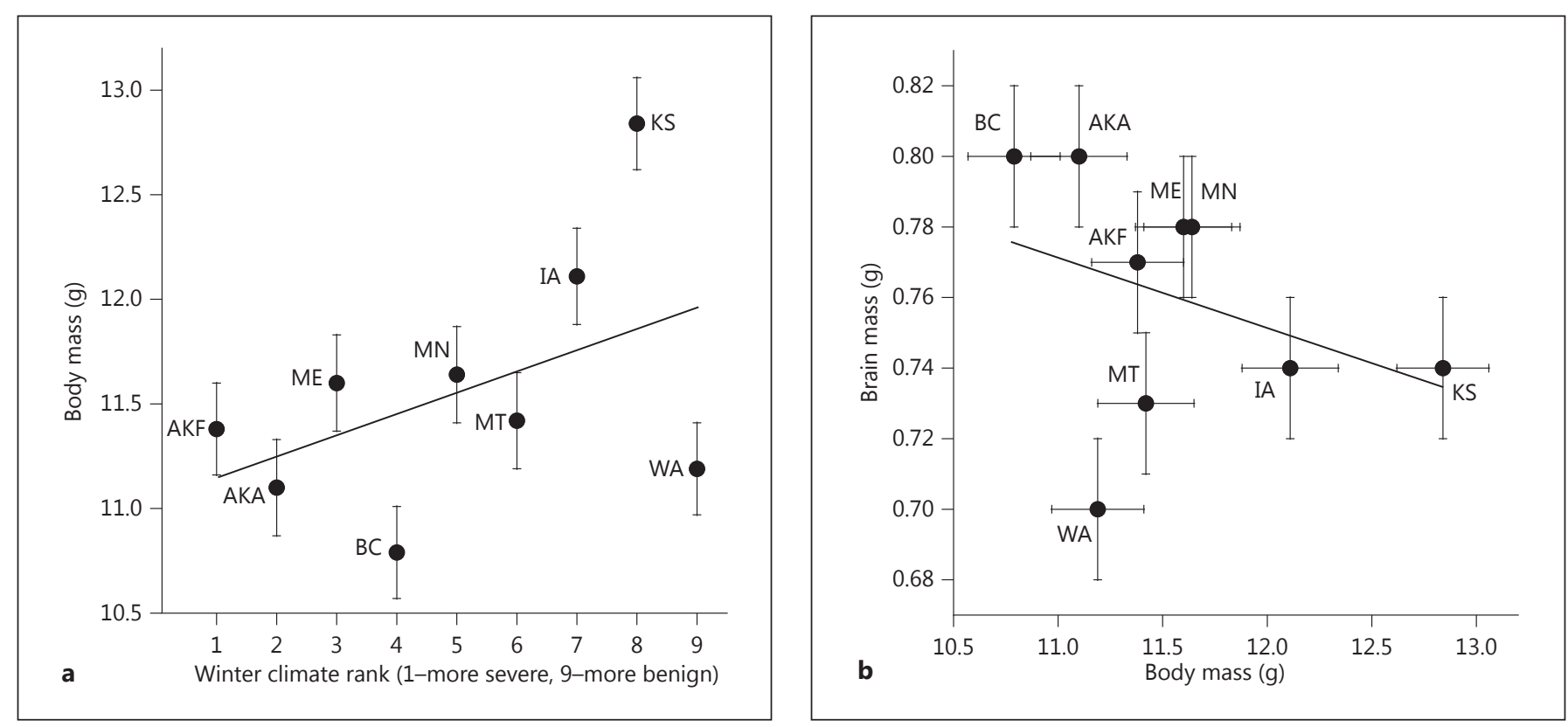

Fig. 2. The relationship between mean population body mass and winter climate harshness (a) and mean body mass and brain mass (b). See table 1 (footnote a) for the abbreviation of the locations.

tion body mass (ordered-heterogeneity test, $\mathrm{r}_{\mathrm{s}} \mathrm{P}_{\mathrm{c}}=0.082$, $\mathrm{k}=9, \mathrm{p}>0.2$ ). At the same time, there was a significant but negative association between mean population tarsus length and mean population wing length (ordered-heterogeneity test, $\mathrm{r}_{\mathrm{s}} \mathrm{P}_{\mathrm{c}}=0.649, \mathrm{p}<0.01$ ); birds with shorter tarsi had longer wings. Such results suggest that mean population tarsus length might not be representative of mean population body size.

Combined, these analyses suggest that harsher environments are associated with larger brains but smaller digestive tracts (both absolute and relative to body mass) and smaller overall body mass. Mean heart mass was not significantly associated with either mean brain mass or winter climate harshness.

\section{Discussion}

Using a comparative approach with multiple populations that likely experience differential selection pressures due to differences in winter climate harshness, our study demonstrated that (1) birds in populations with larger brains (both brain mass and telencephalon volume) had a smaller stomach and gut mass, (2) birds in populations experiencing a harsher winter environment had larger brains (both brain mass and telencephalon vol- ume), but a smaller overall body mass, (3) mean population brain mass was negatively related to mean body mass and (4) there was no significant association between brain mass and heart mass. Combined, these findings suggest that birds from harsher environments are smaller overall, and have bigger brains and smaller digestive tracts, but not smaller hearts. These results are consistent with the expensive-tissue hypothesis, which generally focuses on a trade-off between brain size and digestive tract size.

The expensive-tissue hypothesis extends beyond digestive tract size and includes other 'expensive' organs such as the heart, liver, kidney and skeletal muscle [Aiello and Wheeler, 1995]. Unfortunately, these other tissues were destroyed during perfusion and extraction, with the exception of the heart. Mean heart mass, however, was unrelated to mean-population brain mass. While the heart is energetically costly, it is likely less flexible than the digestive tract. Aiello and Wheeler [1995] also suggest that the heart (and other expensive tissues, e.g. the kidneys and liver) would likely not trade off with brain size as a reduction in heart size would be too great a risk.

At least one previous test of the expensive-tissue hypothesis in birds using an interspecific comparative analysis failed to find an association between the size of the brain, stomach and intestines or the quality of the diet [Isler and van Schaik, 2006]. Unlike this previous study 
which compared diverse species, our comparison concerns multiple populations of the same species that likely show a more recent history of divergence [Pravosudov et al., 2012]. If population differences in brain and stomach size have evolved as a result of climate-related selection on brain size, our study could be more comparable to the most recent experimental study [Kotrschal et al., 2013], which artificially selected for brain size in guppies and found that selection for larger brains was associated with a reduction in gut size, while selection for smaller brains was associated with an increase in gut size. The size of the digestive system in fish did not allow separate measurements of stomach and intestines [Kotrschal et al., 2013] and so it remains unclear whether the entire digestive tract responded to selection on brain size or whether specific parts of the digestive tract drove the differences.

One potential explanation for population differences with regard to the digestive tract might concern differences in diet during the time of collection. Diet quality and gastrointestinal tract size are known to correlate [Chivers and Hladik, 1980; Ricklefs, 1996; Hladik et al., 1999; Fish and Lockwood, 2002; Isler and van Schaik, 2006]. Diets vary substantially among species and can greatly influence whether a trade-off is observed between the size of the brain and the gut [Hladik et al., 1999]. Variation in diet within species is most likely smaller compared to the interspecies variation, but it might still be important in explaining population variation in digestive tract size.

The diet of black-capped chickadees consists of both animal (mainly a wide range of invertebrates) and plant matter, such as seeds and leaves [Smith, 1991; Foote et al., 2010]. Although it is possible and even probable that diet might vary across populations differing in climatic harshness, we could not locate any specific data. It is reported that the diet of chickadees also varies across seasons, shifting from primarily invertebrates during the breeding season to mainly plant matter during the winter [Smith, 1991; Foote et al., 2010]. Available data on seasonal variation in diet do not cover multiple climatic conditions, but it is likely that potential differences between populations might specifically concern the ratio of invertebrate and vegetable-based food.

Seasonal variation in digestive tract morphology (both stomach and guts) is well documented in migratory birds, with some examples for nonmigratory birds [McWilliams and Karasov, 2001]. Variation in digestive tract morphology has been associated with a shift in diet from one type of food to another [Al Dabbagh et al., 1987; Brugger, 1991; Piersma et al., 1993; Novoa et al., 1996;

Chickadees with Bigger Brains Have

Smaller Digestive Tracts
Starck, 1999; McWilliams and Karasov, 2001]. A diet high in fiber and low in nutrients (usually associated with food based on plant matter) appears to be associated with larger gizzards and larger guts (intestines) [Moss, 1972, 1983; Brugger, 1991; Novoa et al., 1996; Starck, 1999; McWilliams and Karasov, 2001]. An increased intake of food (typically associated with a diet of poor nutrients) has also been associated with an increase in digestive tract size and the suggestion that a decreased intake results in a smaller digestive tract [McWilliams and Karasov, 2001]. In shorebirds, the softness of diet was also associated with variations in stomach size [Piersma et al., 1993].

In nonmigratory black-capped chickadees, seasonal changes in the proportion of animal (e.g. invertebrates) versus plant matter ingested are likely [Smith, 1991; Foote et al., 2010], and such changes might result in seasonal variations in digestive tract morphology. However, it is not known whether these changes are similar in different populations or whether birds from some populations rely more on one food type or the other; this could, of course, potentially lead to population variation in the size of the digestive tract [Novoa et al., 1996]. All of our measurements were made in the same season; it is possible that they would have varied according to the different seasons. However, the population differences in digestive tract size reported here are not likely to be simply a reflection of potential differences in diet among populations during the sampling period.

All birds for this study were collected at approximately the same time of year (September to early October) when naturally available food was super-abundant and weather conditions relatively mild across all populations. During that time, invertebrates, the preferred food [Foote et al., 2010], were widely available and it is likely that the diet was similarly invertebrate-biased in all the populations; this would not support plasticity as an explanation. Considering that the summer diet of chickadees is also heavily biased toward invertebrates (e.g. Foote et al. [2010]) and that in gallinaceous birds, diet-based digestive tract changes are known to take 3-4 weeks after a dietary shift [McWilliams and Karasov, 2001], it is not likely that the population differences in chickadees reported here are based on the ratio of invertebrates to plant matter in the diet that differs across different populations. In addition, even if digestive tract morphology does change seasonally due to dietary shifts, the fact that the digestive tract shrinks at all when birds switch to a higher-quality food suggests that there is some cost associated with maintaining a larger digestive tract, and that the digestive tract is metabolically expen- 
sive [Piersma and Lindstrom, 1997]. In line with this, reducing digestive tract size could mean that more energy is supplied to other expensive tissues such as the brain.

It remains possible that differences in digestive tract size across populations might be a plastic response to a different diet. Even if this were the case, a smaller digestive tract would still require less energy and so, in autumn at least, a decrease in digestive tract size would allow for increased energy allocation to the energetically expensive brain. At the same time, brain size and telencephalon volume, in particular, appear to be seasonally stable in chickadees [Hoshooley and Sherry, 2004] and show no environmentrelated variation, in contrast to the volume of the hippocampus [LaDage et al., 2009; Freas et al., 2013]. Overall, it appears unlikely that our results were mainly caused by some local differences specifically at the time of bird collection. Instead, our data are more consistent with longterm population differences in winter climate, reliance on food caches for overwinter survival and winter diet.

We suggest that winter climate harshness might be the main driver of population differences in both brain and digestive tract size. Brain size has previously been related to cognitive abilities and survival in wild birds [Healy and Rowe, 2007], but the causal link between brain size and cognition remains debatable, especially for the interspecific comparisons [Healy and Rowe, 2007; Chittka and Niven, 2009; Pravosudov and Roth, 2013]. In chickadees, we previously demonstrated that birds from harsher climates have better spatial memory to retrieve food caches and also associated differences in hippocampal morphology [Roth and Pravosudov, 2009; Roth et al., 2011; Freas et al., 2012], independent of variation in overall brain size. We also reported better problem-solving abilities unrelated to caching [Roth et al., 2012] and argued that such abilities should be favored in populations experiencing harsh winter climates. Here, we report that chickadees in harsher climates also have significantly larger brains. If harsher climate does provide stronger selection pressure on general learning abilities in addition to the spatial learning abilities required for cache recovery, then our current data suggest that such selection might result in the evolution of a larger brain at the expense of digestive tract size. It is interesting that mean stomach mass was also negatively and significantly associated with mean hippocampal volume; birds with a larger hippocampus have a smaller stomach.

Even if a harsh environment favors a larger brain, enabling higher foraging success and hence increased overwinter survival, what would explain the smaller digestive tract in birds with larger brains? One possible hypothesis is that a reduction in digestive tract size in larger-brained populations is driven by potential winter-climate-related differences between populations in the winter-cachebased diet. The main differences in diet are more likely to occur during the winter and populations in milder climates should rely more on vegetable-based food because animal-based food caches are likely to rot in warmer temperatures. This hypothesis is based on three main features: (1) that the chickadee winter diet is heavily based on previously cached food and chickadees cache both animal- and plant-based food, (2) that colder winters allow for better preservation of animal-based food caches (e.g. invertebrates) and hence for an animal-based diet and (3) that an animal-based diet in harsher environments should reduce the need for a larger digestive tract and therefore results in a reduction in digestive tract size.

Black-capped chickadees rely on food caches during the winter and they are known to cache larger amounts of food during autumn [Brodin, 2005], i.e. food caches comprise a large proportion of their winter diet. The composition of these caches, however, can vary according to winter climate conditions. In harsher environments, winter temperatures are much lower, therefore animal matter, such as invertebrates, can be preserved for a long time when cached. Indeed, Brodin [2005] reported that 33\% of the food caches made by black-capped chickadees at one of our sampled northern locations (at the same period of time as the collection of birds in our study) with a harsh winter climate, i.e. B.C., Canada, consisted of animal matter (invertebrates) while the rest consisted of the seeds of conifers. At the same time, the chickadees had a mostly (65\%) invertebrate-based diet [Brodin, 2005], indicating that, at the time of our bird collection, birds in harsh climates still ate invertebrates.

It is well known that most food-caching parids regularly cache invertebrates in harsh northern environments [Haftorn, 1956; Pravosudov, 1985]. In more moderate climate, winters are warmer and the nutrients of animalbased caches would likely degrade due to rotting. Such climate differences might favor caching more plant matter and less nutritious foods in more moderate environments and more animal matter in harsher environments. This pattern is consistent with our finding of differences in stomach size according to population; birds in milder environments might have larger stomachs for dealing with food that is less nutritious and requires increased mechanical processing and a longer retention time [McWilliams and Karasov, 2001]. Chickadees in harsher environments, on the other hand, could shift their diet to- 
ward invertebrates which require less gastrointestinal processing, because colder temperatures allow the caching of animal-based food.

Stomach size can be reduced without any loss in absorptive capacity [Hladik et al., 1999; Kauffman, 2003] while still decreasing metabolic demands [Kauffman, 2003]. However, a larger stomach is related to digestive and absorptive efficiency (i.e. the amount of food and nutrients processed over time) [Gross et al., 1985; Penry and Jumars, 1987; Ricklefs, 1996]. At the same time, the gizzard in birds is mainly used to mechanically process and crush food but also serves to break down food chemically and control the flow of food through the alimentary tract [Svihus, 2011]. A diet in milder environments biased towards vegetable matter like seeds, might require a larger stomach and a larger gut (as a result of the increased fiber intake and increased softness of the diet). Animal matter, on the other hand, might be digested more efficiently, and, combined with the colder-temperature-related longevity of animal-matter-based caches; this potentially explains the smaller stomach and gut size in populations from harsher winter environments. These potential differences in the quality of the diet between chickadee populations might favor changes in digestive tract size, which, in turn, would favor the evolution of differences in brain size based on differential selection pressures on cognitive ability. In primates and humans, for example, this is the leading explanation for the evolution of a larger brain: the increase in diet quality allowed for a reduction in gut size and, in turn, for the evolution of a larger brain [Roth and Dicke, 2005].

Another interesting finding is that birds from harsher environments with larger brains were actually smaller, suggesting a reduction in overall body size, which is opposite to what would be expected from Bergmann's rule [Rensch, 1938; Blackburn et al., 1999]. Body mass is known to vary both seasonally and during the day, but in our study, all populations were compared during the same season (autumn) and birds were captured during the first part of the day and measured at approximately the same time prior to perfusion, so the results were comparable. Finally, using multiple individuals to estimate the population means increased the reliability of our population estimates. It is not clear why birds in harsher environments would be smaller. Smaller body size was associated with smaller stomach size, and so population variations in stomach mass might explain, at least partly, variations in body mass. The maximum difference in stomach mass between populations was only $0.303 \mathrm{~g}$, however, whereas the maximum difference in body mass was $2.05 \mathrm{~g}$ (almost 7 times more), suggesting that stomach mass explains only a small fraction of variations in body mass.

Interestingly, the mean population tarsus length showed no significant associations with either winter climate harshness or mean brain mass, but was negatively associated with wing length. This may suggest potential population differences in foraging tactics based on flight and also that tarsus length might not provide a true reflection of population variation in body size.

Overall, our results are consistent with the expensivetissue hypothesis. They suggest that a winter climate might drive population-level differences in brain size, in addition to hippocampal morphology, but that an increase in brain size is associated with a reduction in digestive tract, possibly due to differences in the diet and the composition of food caches. Colder climates allow for better preservation of stored animal matter (the invertebrates frequently cached by chickadees) which is more efficient for digestion but also generates higher demands on cognitive ability, including spatial memory, crucial for more efficient foraging and the retrieval of cached food items.

\section{Acknowledgements}

All birds used for this study were collected for our 2 previous studies (Roth and Pravosudov [2009] and Roth et al. [2011]) and so all required permits have already been published. Comments from three anonymous reviewers significantly improved the manuscript.

\section{References}

Chickadees with Bigger Brains Have

Smaller Digestive Tracts
Aiello LC, Wheeler P (1995): The expensive-tissue hypothesis: the brain and the digestive system in human and primate evolution. Curr Anthropol 36:199-221.

Al Dabbagh KY, Jiad JH, Waheed IN (1987): The influence of diet on the intestine length of the white-cheeked bulbul. Ornis Scand 18:150152. Barrickman NL, Lin MJ (2010): Encephalization,
expensive tissue, and energetics: an examina-
tion of the relative costs of brain size in strep-
sirrhines. Am J Phys Anthropol 143:579-590.
Blackburn TM, Gaston KJ, Loder N (1999): Geo-
graphic gradients in body size: a clarification
of Bergmann's rule. Divers Distrib 5:165-174. 
Brodin A (2005): Hippocampal volume does not correlate with food-hoarding rates in the black-capped chickadee (Poecile atricapillus) and willow tit (Parus montanus). Auk 122: 819-828.

Brugger KE (1991): Anatomical adaptation of the gut to diet in red-winged blackbirds (Agelaius phoeniceus). Auk 108:562-567.

Chittka L, Niven J (2009): Are bigger brains better? Curr Biol 19:R995-R1008.

-Chivers DJ, Hladik CM (1980): Morphology of the gastrointestinal tract in primates: comparisons with other mammals in relation to diet. J Morphol 166:337-386.

-Fish JF, Lockwood CA (2002): Dietary constraints on encephalization in primates. Am J Phys Anthropol 120:171-181.

Foote JR, Mennill DJ, Ratcliffe LM, Smith SM (2010): Black-capped chickadee (Poecile atricapillus); in Poole A (ed): The Birds of North America Online. Ithaca, Cornell Lab of Ornithology. http://bna.birds.cornell.edu/bna/ species/039

Freas CA, Bingman K, LaDage LD, Pravosudov VV (2013): Untangling elevation-related differences in the hippocampus in food-caching mountain chickadees: the effect of a uniform captive environment. Brain Behav Evol 82: 199-209.

Freas CA, LaDage LD, Roth II TC, Pravosudov VV (2012): Elevation-related differences in memory and the hippocampus in mountain chickadees (Poecile gambeli). Anim Behav 84 121-127.

Gross JE, Wang Z, Wunder BA (1985): Effects of food quality and energy needs: changes in gut morphology and capacity of Microtus ochrogaster. J Mammal 66:661-667.

Haftorn S (1956): Contribution to the food biology of tits especially about storing of surplus food. IV. A comparative analysis of Parus at ricapillus $\mathrm{L}, P$. cristatus $\mathrm{L}$ and $P$. ater $\mathrm{L}$. Kongelige Norske Videnskabers Selskabs Skrifter 4:1-54.

Healy SD, Rowe C (2007): A critique of comparative studies of brain size. Proc R Soc B 274: 453-464.

Hladik CM, Chivers DJ, Pasquet P (1999): On diet and gut size in non-human primates and humans: is there a relationship to brain size? Curr Anthropol 40:695-697.

Hoshooley JS, Sherry DF (2004): Neuron production, neuron number, and structure size are seasonally stable in the hippocampus of the food-storing black-capped chickadee (Poecile atricapillus). Behav Neurosci 118:345-355.
Isler K, van Schaik CP (2006): Costs of encephalization: the energy trade-off hypothesis tested on birds. J Hum Evol 51:228-243.

Jones KE, MacLarnon AM (2004): Affording larger brains: testing hypotheses of mammalian brain evolution on bats. Am Nat 164:E20E31.

Kauffman JA (2003): On the expensive-tissue hypothesis: independent support from highly encephalized fish. Curr Anthropol 44:705707.

Kotrschal A, Rogell B, Bundsan en A, Svensson B, Zajitschek S, Brannstrom I, Immler S, Maklakov AA, Kolm N (2013): Artificial selection on relative brain size in the guppy reveals costs and benefits of evolving larger brain. Curr Biol 23:168-171.

LaDage LD, Roth TC II, Fox RA, Pravosudov VV (2009): Effects of captivity and memorybased experiences on the hippocampus in mountain chickadees. Behav Neurosci 123: 284-291.

McWilliams SR, Karasov WH (2001): Phenotypic flexibility in digestive system structure and function in migratory birds and its ecological significance. Comp Biochem Physiol A Mol Integr Physiol 128:579-593.

-Mink JW, Blumenschine RJ, Adams DB (1981): Ratio of central nervous system to body metabolism in vertebrates - its constancy and functional basis. Am J Physiol 241:R203R212.

Moss R (1972): Effects of captivity on gut length in red grouse. J Wildl Manage 36:99-104.

Moss R (1983): Gut size, body weight, and digestion of winter foods by grouse and ptarmigan. Condor 85:185-193.

Navarrete A, van Schaik CP, Isler K (2011): Energetics and the evolution of human brain size. Nature 480:91-94.

Novoa FF, Veloso C, Lopez-Calleja MV, Bozinovic F (1996): Seasonal changes in diet, digestive morphology and digestive efficiency in the rufous-collared sparrow (Zonotrichia capensis) in central Chile. Condor 98:873876.

Penry DL, Jumars PA (1987): Modeling animal guts as chemical reactors. Am Nat 129:69-96.

-Piersma T, Koolhaas A, Dekinga A (1993): Interactions between stomach structure and diet choice in shorebirds. Auk 110:552-564.

Piersma T, Lindstrom A (1997): Rapid reversible changes in organ size as a component of adaptive behaviour. Trends Ecol Evol 12:134-138.

Pravosudov VV (1985): Search for and storage of food by Parus cinctus lapponicus and P. montanus borealis (Paridae). Zool Zhurnal 64: 1036-1043.
Pravosudov VV, Roth TC II (2013): Cognitive ecology of food-hoarding: the evolution of spatial memory and the hippocampus. Annu Rev Ecol Evol Syst 44:173-193.

Pravosudov VV, Roth TC II, Forister M, LaDage LD, Burg T, Braun M, Davidson B (2012): Population genetic structure and its implications for adaptive variation in memory and the hippocampus on a continental scale in food-caching black-capped chickadees. Mol Ecol 21:4486-4497.

Rensch B (1938): Some problems of geographical variation and species formation. Proc Linn Soc Lond 150:275-285.

Rice WR, Gaines SD (1994): Extending nondirectional heterogeneity tests to evaluate simply ordered alternative hypotheses. PNAS 91: 225-226.

Ricklefs RE (1996): Morphometry of the digestive tracts of some passerine birds. Condor 98: 279-292.

Roth G, Dicke U (2005): Evolution of the brain and intelligence. Trends Cogn Sci 9:250-257.

- Roth TC 2nd, LaDage LD, Freas C, Pravosudov VV (2012): Variation in memory and the hippocampus across populations with different climates: a common garden approach. Proc $\mathrm{R}$ Soc B 279:402-410.

Roth TC 2nd, LaDage LD, Pravosudov VV (2011): Variation in hippocampal morphology along an environmental gradient: controlling for the effect of day length. Proc R Soc B 278: 2662-2667.

Roth TC 2nd, Pravosudov VV (2009): Hippocampal volume and neuron numbers increase along a gradient of environmental harshness: a large-scale comparison. Proc R Soc B 276: 401-405.

Smith SM (1991): The Black-Capped Chickadee: Behavioral Ecology and Natural History. New York, Comstock Pub Assoc.

- Starck JM (1999): Phenotypic flexibility of the avian gizzard: rapid reversible and repeated changes of organ size in response to changes in dietary fibre content. J Exp Biol 202:31713179 .

Svihus B (2011): The gizzard: function, influence of diet structure and effects on nutrient World Poultry Sci J 67:207-224.

Warren DL, Iglesias TL (2012): No evidence for the 'expensive-tissue hypothesis' from an intraspecific study in a highly variable species. J Evol Biol 25:1226-1231. 